\title{
Seagrass colonization: biomass development and shoot demography in Cymodocea nodosa patches
}

\author{
Carlos M. Duarte ${ }^{1}$, Kaj Sand-Jensen ${ }^{2}$ \\ ${ }^{1}$ Centro de Estudios Avanzados, Camino de Santa Barbara, E-17300 Blanes, Gerona, Spain \\ ${ }^{2}$ Freshwater Biological Laboratory, University of Copenhagen, Helsingersgade 51, DK-3400 Hillerød, Denmark
}

\begin{abstract}
Patches of Cymodocea nodosa colonizing highly mobile sandy sediments were studied to determine the temporal and spatial course of biomass and demographic development. Results show (1) a close coupling between rhizome growth and shoot density and biomass; (2) an average biomass accumulation rate of ca $250 \mathrm{~g}$ fresh wt m $\mathrm{m}^{-2} \mathrm{yr}^{-1}$ for rhizomes and $480 \mathrm{~g} \mathrm{~m}^{-2} \mathrm{yr}^{-1}$ for shoots; and (3) a close relationship between plant biomass and distance from patch edge. Short shoots are produced in annual cohorts, subject to an average mortality of ca 1.0 exponential unit $\mathrm{yr}^{-1}$ regardless of cohort age, but shoot mortality decreases with distance from patch edge. Patch maintenance is achieved by shoot recruitment rates closely matching shoot mortality rates. Mean shoot age, variability in shoot age structure, and associated shoot characteristics (i.e. length and number of standing leaves), increase with time after patch establishment. These results demonstrate the importance of shoot recruitment and mortality for the maintenance and growth of $C$ nodosa patches and, hence, for seagrass recovery.
\end{abstract}

\section{INTRODUCTION}

Seagrass recovery from physical disturbance and catastrophic decline involves the colonization by propagules and the overgrowth of bare substratum through rhizome expansion (Duarte \& Sand-Jensen 1990). Rhizome growth is supported by reallocation of photosynthetic products, and must, therefore, be closely coupled to the development of leaf-bearing shoots. Furthermore, biotic communities associated with seagrasses often use their leaves as substratum or refuge, and their recovery relies, therefore, on the development of above-ground material. Thus, knowledge of the coupling between rhizome growth and shoot development is important for forecasting the recovery of seagrasses and their associated biota.

As seagrass colonization proceeds, the age structure of growing seagrass patches becomes increasingly complex, with a gradient from young colonizing shoots in the periphery to older shoots at the patch origin. Maintenance of the seagrass community over the colonized substratum requires that shoot senescence and subsequent mortality be balanced by shoot recruitment. This should lead to an increasingly skewed shoot age distribution with time since the plant became established. Because new shoots are often smaller and, therefore, less productive than mature shoots, shoot mortality and recruitment should generate considerable small-scale variability in shoot demography and growth within expanding patches.

Here we examine the relationship between rhizome and shoot development in patches of the seagrass Cymodocea nodosa colonizing highly dynamic sandy sediments in a shallow NW Mediterranean bay (Alfaques Bay, Ebro Delta, NE Spain; cf. Duarte \& SandJensen 1990). Patterns of rhizome and shoot biomass development during colonization are described by examining the biomass build-up from the patch edge (newly colonized substratum) to the patch origin. We then describe short-shoot demography by examining age structure along the patches, and in relation to the time elapsed since the stand was established. Because age structure is the outcome of shoot recruitment and mortality, we quantify these rates and search for patterns to explain the variability in shoot recruitment and mortality within the patches. Finally, we assess the age-dependence of shoot characteristics (i.e. number of leaves per shoot and leaf length).

\section{METHODS}

Seagrass biomass, short shoot characteristics, and short shoot age structure were studied in 10 
Cymodocea nodosa patches (sampled between 8 and 25 July 1989) selected to cover a wide range in patch size (length of main axis $<1 \mathrm{~m}$ to $25 \mathrm{~m}$ ). At each patch, we placed a transect along the main axis, and, in the larger (>5 m) patches, a transect perpendicular to the main axis through its geometric centre (Duarte \& SandJensen 1990). We then located 3 to 15 , depending on patch size, uniformly spaced stations along each transect. At each station we placed a $0.04 \mathrm{~m}^{2}$ quadrat and harvested all shoots and rhizome fragments within the quadrat. The plants were kept refrigerated until processed. After rinsing the plants and removing excess water, we weighed rhizomes and leaf-bearing shoots to calculate their biomass as fresh weight (FW) and counted all shoots within the sample. We then estimated shoot age, counted the number of leaves and measured the length of the longest standing leaf of all shoots (or a subsample of at least 40 shoots in dense samples).

Shoot age was estimated as the product of the total number of leaves produced during its life-span (i.e. number of standing leaves plus leaf scars from shed leaves $=$ number of plastochrone intervals, P.I.'s) multiplied by the mean time elapsed between the production of successive leaves (about $28 d_{\text {; }}$ Duarte \& Sand-Jensen 1990). We then calculated the ages of all shoots in the sample to determine the age of the oldest shoot present, which provides an estimation of the minimum time elapsed since colonization (Duarte \& Sand-Jensen 1990). The station containing the oldest leaf-bearing shoot was assumed to be at, or close, to the position where the patch was initiated. These estimates of time elapsed after colonization of the different stations were then used to calculate the rates of biomass increase with time.

Shoot demography was characterised by 4 descriptors: (1) mean shoot age; (2) coefficient of variation of shoot age, which measures the extent of demographic heterogeneity of the stand; (3) shoot mortality (as exponential units $\mathrm{yr}^{-1}$ ) derived from the number of shoots in consecutive cohorts; and (4) shoot recruitment (as exponential units $\mathrm{yr}^{-1}$ ) in the year preceding sampling, derived from the proportion of all shoots that were $<1$ yr. Shoot recruitment here derives almost exclusively from vegetative propagation (i.e. rhizome elongation), for seedlings were very rare (about $0.05 \mathrm{~m}^{-2}$ ) and showed limited rhizome growth (Duarte \& SandJensen 1990).

Relationships between variables were described using linear least squares regression analysis, and the strength of the relationships was described using Pearson correlation coefficients. Variables were log-transformed when necessary to comply with the requirements of these analyses. Patterns of biomass development with distance from the patch edge were examined using LOWESS (robust locally weighted regression;
Cleveland 1979) smoothing. This technique allows the description of trends in scatter plots without the restrictions imposed by regression analysis (Cleveland 1979).

\section{RESULTS}

\section{Biomass development in growing patches}

Shoot density and shoot biomass were strongly related (Fig. 1), as described by the regression equation,

$$
\begin{aligned}
& \text { Log shoot biomass }\left(\mathrm{gW} \mathrm{m} \mathrm{m}^{-2}\right) \\
& =-1.1+1.2 \text { Log shoot density }\left(\text { no. } \mathrm{m}^{-2}\right) \\
& \qquad \mathrm{R}^{2}=0.86 ; \mathrm{n}=37 ; \mathrm{p}<0.0001
\end{aligned}
$$

Similarly, shoot density and rhizome biomass were strongly related (Fig. 1), as described by the regression equation,

Log shoot density (no. $\mathrm{m}^{-2}$ )

$$
\begin{gathered}
=1.0+1.1 \text { Log rhizome biomass }\left(\mathrm{g} \mathrm{FW} \mathrm{m}^{-2}\right) \\
\mathrm{R}^{2}=0.89 ; \mathrm{n}=37 ; \mathrm{p}<0.0001
\end{gathered}
$$

These relationships (Fig. 1) demonstrate the postulated link between rhizome growth and shoot development during seagrass colonization. Shoot and rhizome biomass increased from patch edge to patch origin, indicating that plant biomass increased with the time elapsed since colonization. The average correlation coefficient between rhizome biomass and the time
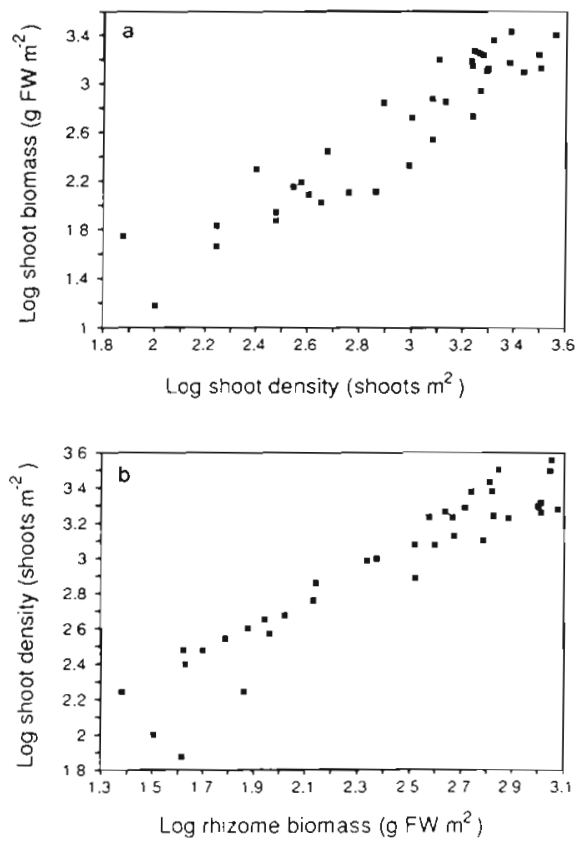

Fig. 1. Cymodocea nodosd. Relationships between (a) rhizome biomass and shoot density, (b) shoot density and shoot biomass for all stations examined 
elapsed since establishment was $0.81 \pm 0.08$ (p < $0.0001)$, and between shoot biomass and the time elapsed since establishment was $0.80 \pm 0.07 \mathrm{SE}(\mathrm{p}<$ 0.0001 ). The average slopes of these relationships indicated that the average rate of biomass increase was 256 \pm 70 (SE) g FW m ${ }^{-2} \mathrm{yr}^{-1}$ for rhizome biomass and 483 \pm 150 (SE) g FW m${ }^{-2} \mathrm{yr}^{-1}$ for shoot biomass.

Biomass maxima were always located at or near the geometric centre of the patches, whereas patch origin was consistently displaced from the geometric centre (Duarte \& Sand-Jensen 1990). In addition, the rate of biomass increase with increasing distance from the patch edge did not differ among patches (multiple ttest, $\mathrm{p}>0.10$ ). Thus rhizome and shoot biomass were related both to the distance from patch edge and the time elapsed since colonization, as demonstrated by significant ( $t$-test, $\mathrm{p}<0.001$ ) slopes of both variables in multiple regression analysis of biomass variability.

Examination of the patterns of biomass change across patches showed a steep increase in rhizome biomass from patch edge up to a maximum at about $6 \mathrm{~m}$ from the patch edge (Fig. 2). Because rhizome biomass is closely related to shoot density, the patterns of shoot density and shoot biomass with increasing distance from the patch edge were similar to that for rhizome biomass (Fig. 2). Because shoot weight did not appear to show a plateau at intermediate distances, but increased monotonously along the range of distances from patch edge (Fig. 2), shoot biomass did not reach a maximum until about $8 \mathrm{~m}$ from the patch edge (Fig. 2).

\section{Age dependence of shoot characteristics and shoot age distribution}

Shoot characteristics were closely related to shoot age. The number of standing leaves per shoot increased with shoot age to reach a plateau at about 8 P.I.'s (ca 0.7 yr; Fig. 3a). Shoot length (i.e. the length of the longest standing leaf) also increased with shoot age, reaching a plateau at ca 20 P.I.'s (ca $1.5 \mathrm{yr}$; Fig. 3b). In addition, average shoot length was strongly related to the time elapsed since colonization $(r=0.65$, $\mathrm{p}<0.0001$ ), and, consequently, to shoot biomass $(\mathrm{r}=$ $0.85, \mathrm{p}<0.0001$ ).

The shoot age distribution obtained when compounding all the data gathered (about 1800 shoot age estimates) was polymodal (Fig. 4), reflecting the existence of shoot cohorts. These cohorts are produced annually, with most shoots appearing from May to July (Perez 1989), as demonstrated by separation between cohort modes of $14 \pm 0.6$ (SE) P.I.'s (Fig. 4), which corresponds closely with the number of leaves produced in a year (Perez 1989, Duarte \& Sand-Jensen 1990). The existence of annual shoot cohorts derives, in
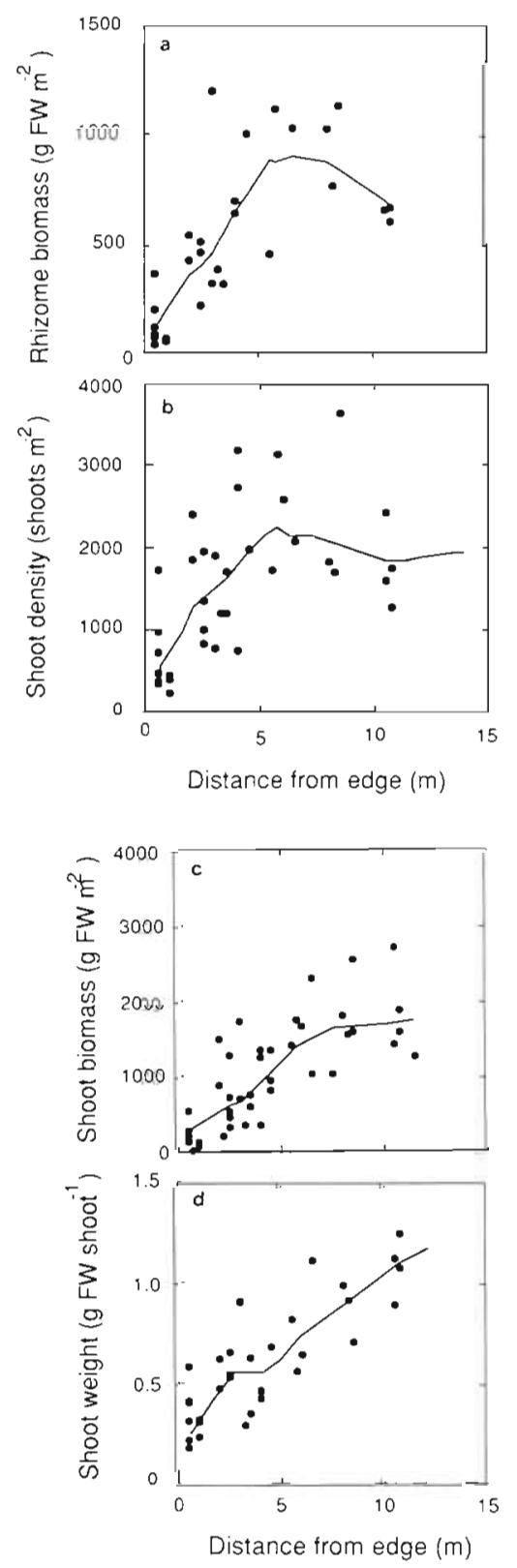

Fig. 2. Cymodocea nodosa. Trends of (a) rhizome biomass, (b) shoot density, (c) shoot biomass, and (d) shoot weight, with increasing distance from the patch edge for the different stations sampled

turn, from the existence of annual cycles in rhizome growth (Caye \& Meinesz 1985), reflected in seasonal variability in rhizome internodal length (Fig. 5). Thus, we pooled data in year classes for further analyses.

\section{Shoot mortality and recruitment}

Shoot abundance declined considerably with increasing age (Fig.4), indicating substantial shoot mortality. The oldest shoot collected was 92 P.I.'s (i.e. 

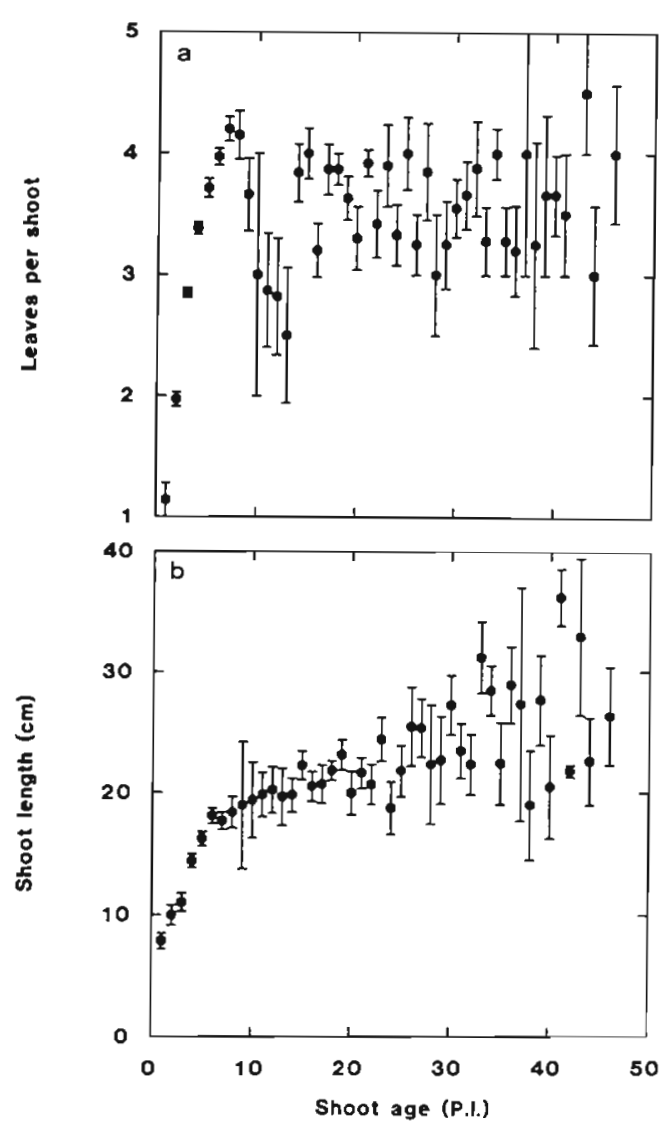

Fig. 3. Cymodocea nodosa. (a) Number of standing leaves and (b) shoot length (as the length of the longest standing leaf) as functions of shoot age. Mean values $\pm \mathrm{SD}$

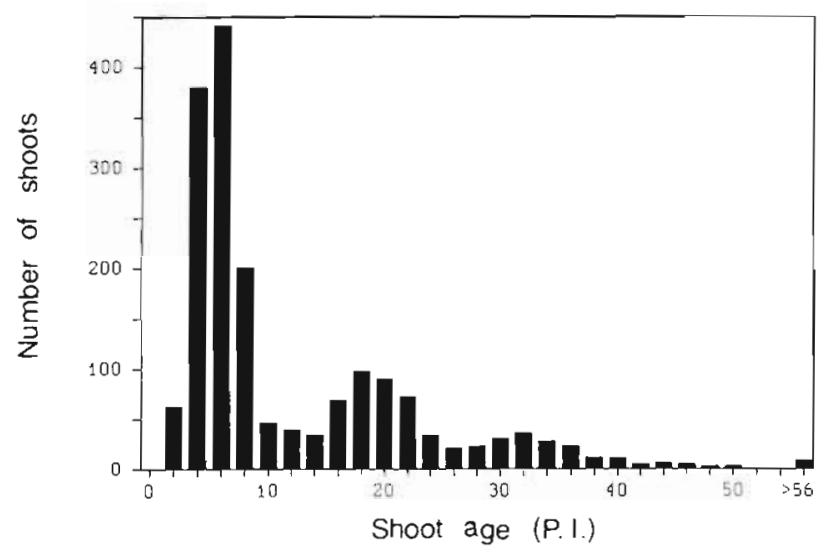

Fig. 4. Cymodocea nodosa. Shoot age distribution for the population studied, constructed by pooling all $(>1800)$ shoot age estimates

ca 7 yr) old. Shoot mortality was examined by calculating within-station mortality rates for the different cohorts. This analysis showed that differences in mortality rate among shoot cohorts were small (Fig. 6) compared to spatial (i.e. among all stations) variability in shoot mortality (i.e. standard deviations in Fig. 6). For

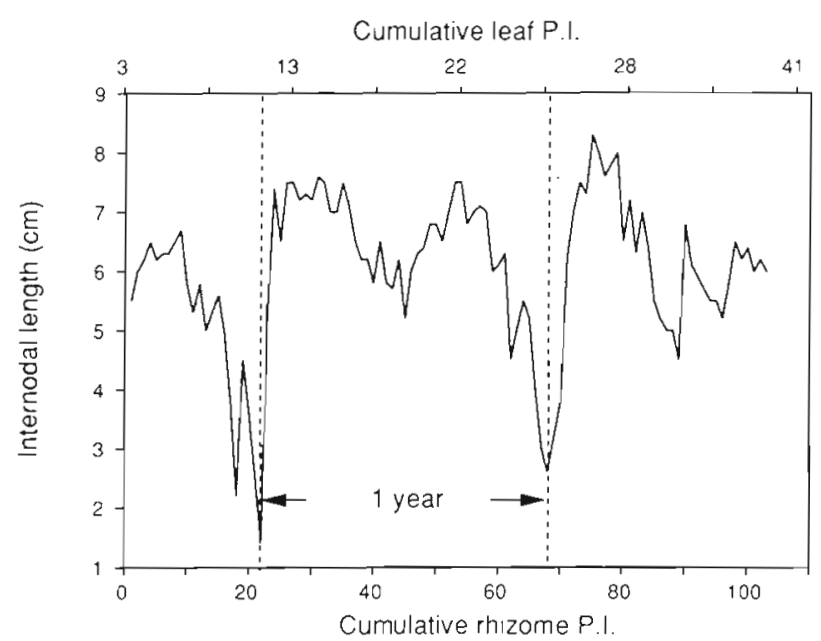

Fig. 5. Cymodocea nodosa. Reconstruction of the internodal length sequence for a fast-growing rhizome as a function of the cumulative number of internodes. Scale above represents age (as leaf plastochrone intervals, P.I.'s) of the short shoots encountered along the rhizome. The annual cycle evident in the data represents ca 13 leaf P.I.'s $\mathrm{yr}^{-1}$ and 46 rhizome internodes $\mathrm{yr}^{-1}$

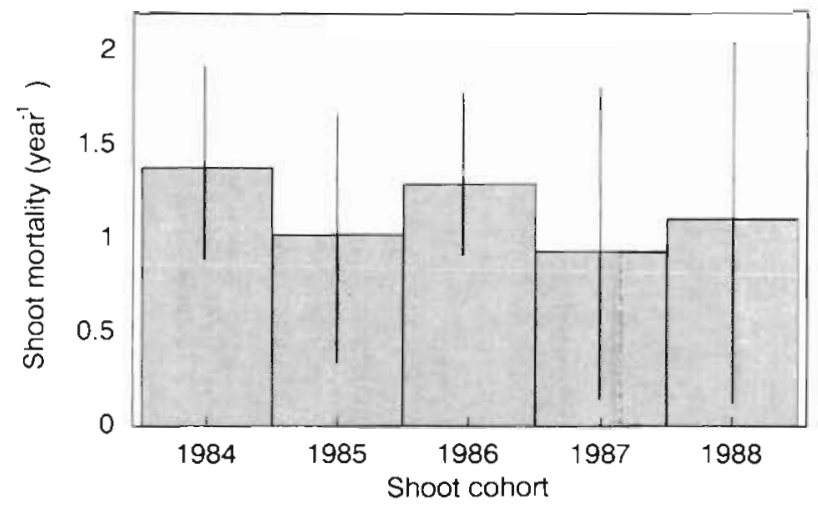

Fig. 6. Cymodocea nodosa. Average $( \pm 1 \mathrm{SD})$ estimated mortality rates between 1988 and 1989 for shoots of different cohorts sampled in different locations. Figures on abscissa refer to year of appearance of the cohort examined. Mortality reported in exponential units $\mathrm{yr}^{-1}$

instance, shoot mortality of the cohort produced in 1988 varied among stations from <0.1 to 4.47 exponential units $\mathrm{yr}^{-1}(\mathrm{CV}=0.89)$, corresponding to annual mortalities between $<10$ and $99 \%$. We restricted further analysis of shoot mortality to the cohort produced in 1988, for which sampling size was greatest.

Spatial variability in shoot recruitment was also considerable $\left(\right.$ mean $=1.26$ exponential units $\mathrm{yr}^{-1}, \mathrm{CV}=$ $0.70)$, ranging from no recruitment to 3.6 exponential units $\mathrm{yr}^{-1}$. The hypothesized balance between shoot mortality and recruitment necessary for patch maintenance was confirmed by the fact that the stations that showed high shoot mortality also showed high recruitment ( $r=0.90 ; p<0.0001 ;$ Fig. 7).

Shoot demography was strongly coupled to Cymo- 


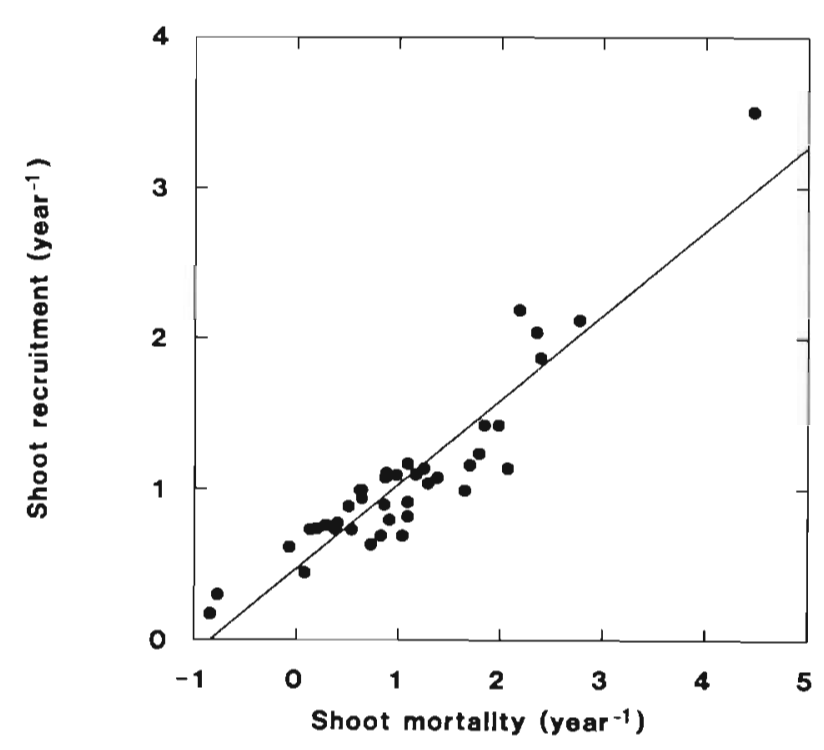

Fig. 7 Cymodocea nodosa. Relationship between mortality of shoots produced in 1988 and recruitment of shoots in 1989. Both in exponential units $\mathrm{yr}^{-1}$

docea nodosa colonization dynamics. The age structure of their shoots changed as the time elapsed since establishment increased, resulting in greater mean shoot age $(r=0.64, p<0.0001)$, and an increasingly complex age structure (measured as the within-station coefficient of variation of shoot age; $r_{\text {agecv/me }}=0.62$, $\mathrm{p}<0.0001$ ). Regression analysis between mean age and time after establishment (in plastochrone intervals, P.I.),

$$
\begin{gathered}
\text { Log mean age (P.I.) }=0.18+0.60 \text { Log time (P.I.) (3) } \\
\left.\mathrm{R}^{2}=0.65 ; \mathrm{SE}_{\text {slope }}=0.06 ; \mathrm{p}<0.0001\right)
\end{gathered}
$$

demonstrates that mean shoot age does not increase linearly with increasing time after colonization $\left(\mathrm{H}_{0}\right.$ : slope $=1$; t-test, $\mathrm{p}<0.001$ ), because recruitment of new shoots and mortality of older ones tend to lower the mean shoot age. In addition, variability among neighbouring shoots (reflected in the coefficient of variation of their length) increased with increasing age variability $\left(r_{\text {length }} \mathrm{cv} / \mathrm{agec} \mathrm{v}=0.65, \mathrm{p}<0.001\right)$, whereas shoot recruitment and mortality rates decreased with increasing mean shoot age $\left(\mathrm{r}_{\text {age/recruitment }}=-0.83\right.$ and $\mathrm{r}_{\text {age/mortalty }}=-0.55, \mathrm{p}<0.001$, respectively) .

\section{DISCUSSION}

The results reported demonstrate the close coupling between the development of Cymodocea nodosa rhizomes and leaf-bearing shoots, thereby confirming the rhizome dependence of seagrass development postulated by Tomlinson (1974). This dependence is expressed as strong relationships between the development of rhizome and shoot biomass (Fig. 1), and between shoot mortality and recruitment (Fig. 7), necessary to ensure seagrass maintenance. In addition, our results demonstrate the time-dependence of structural and demographic properties of colonizing C. nodosa. As the time after colonization increases, mean shoot age and small-scale variability in shoot age and length increase, and relative shoot recruitment and mortality decline.

Patch expansion in Cymodocea nodosa proceeds by centrifugal extension of fast-growing stolons into bare substratum and subsequent branching to occupy the space (Duarte \& Sand-Jensen 1990). Thus, biomass increase with time after colonization derives, at least partially, from progressive occupation of the bare space between the expanding stolons. This pattern appears to hold for other seagrass species, as suggested by increased biomass from a minimum at the patch edge to a maximum at the patch centre in some patches of other seagrass species (e.g. Zostera marina, Orth 1977 ; Thalassia testudinum, Zieman 1972).

Biomass accumulation of Cymodocea nodosa, however, does not proceed continuously, as suggested by a plateau in plant biomass observed beyond 6 to $8 \mathrm{~m}$ from the patch edge (Fig. 2). which suggests that crowding may prevent further biomass increase. The apparent importance of density-dependent constraints to $C$. nodosa in the population examined probably involves resource (notably phosphorus; Perez et al. unpubl.) limitation. The average rhizome biomass attained at the plateau was ca $800 \mathrm{~g} \mathrm{FW} \mathrm{m}^{-2}$ (Fig. 2b). Because living rhizomes are typically restricted to the upper $5 \mathrm{~cm}$ of the sediment (Duarte unpubl.), the maximum sediment volume occupied by $C$. nodosa rhizomes represents (assuming a rhizome density of 1.1) ca $1.5 \%$ of the available space, which is close to the value of $3 \%$ found to represent the maximum possible rhizome concentration for a terrestrial perennial grass (Ovington 1953). Similarly, the plateau in above-ground biomass with distance from patch edge (Fig. 2c) may derive from shoot crowding, because shoot weight at this maximum (ca $0.8 \mathrm{~g} \mathrm{FW} \mathrm{shoot}^{-1}$ ) was close to the maximum possible (ca $0.3 \mathrm{~g} \mathrm{FW}$ shoot $^{-1}$ ) for the observed shoot density (ca 2200 shoots $\mathrm{m}^{-2}$ ), as calculated from the general relationship between mean shoot weight and shoot density for submerged macrophytes reported by Duarte \& Kalff (1987). Because seagrass communities in deeper waters may reach biomasses above those found here for shallow Cymodocea nodosa populations (Stevenson 1988. Duarte 1989), crowding should probably be examined in volumetric densities (i.e. plant volume per unit available space; Duarte 1990) instead of areal densities.

Patch maintenance was, as predicted, achieved by closely balanced shoot mortality and recruitment rates, as reflected in the strong relationships between these 
processes (Fig. 7). The balance between shoot recruitment, that results from branching of fast-growing rhizomes to occupy the space, and mortality rates in recently colonized areas (i.e. at the patch front) is particularly important because it determines whether the patches expand (i.e. recruitment $>$ mortality) or recede (i.e. mortality $>$ recruitment). The highly dynamic nature of patch fronts is reflected in that the maximum rates of recruitment and mortality were observed there. Both recruitment and mortality rates decline with patch development. The reduced recruitment may be related to a hypothetical reduction in rhizome extension derived from crowding, whereas the decrease in shoot mortality with increasing patch development is probably the result of increasing shelter within larger patches. Thus, the observed decrease in shoot mortality with increasing average shoot age is probably spurious, as suggested by the remarkable constancy of mortality rates of different shoot cohorts (i.e. different age; Fig.6), and probably reflects the more protected position of older shoots. As seagrass patches expand, changes in shoot recruitment and mortality generate important variability in shoot age structure within the patches, from relative uniform at the patch front to an increasingly skewed age distribution towards the patch origin. Because shoot age influences shoot size (Fig. 3) and growth (Perez et al. 1990), this process also results in the increase in smallscale variability in shoot characteristics from the patch front to the patch origin.

Seagrass growth is often modelled from the environmental conditions (e.g. light and nutrients) conducive to plant (usually leaf) growth (e.g. Short 1980, Wetzel \& Neckles 1986, Zimmerman et al. 1987). The close link between environmental conditions and seagrass growth implicit in those models, which often ignore small-scale habitat variability, leads to the expectation of relatively uniform vegetation in areas where no discernible differences in environmental conditions (sediments, light, and current characteristics) can be observed prior to patch establishment. However, the considerable heterogeneity, both at the stand (e.g. biomass) and shoot (e.g. mean age) level, observed here indicates that forecasting development of seagrass patches requires consideration of both broad environmental conditions, and small-scale variability in plant characteristics (e.g. age distribution) subject to change during patch ontogeny.

The spatial variability in biomass and shoot characteristics of colonizing seagrasses has (1) an aleatory component, associated with, apparently random, seedling establishment, that sets the difference between colonized and bare substratum; and (2) an intrinsic component responsible for the development of variability in shoot size and age within colonized areas. In addition, seagrass development alters habitat conditions, such as current (e.g. Fonseca et al. 1982, 1983, Thayer et al. 1984) and sediment dynamics (Fonseca et al. 1983, Thayer et al. 1984). Because the extent of these changes in habitat conditions depends on seagrass development (cf. Thayer et al. 1984), the importance of autogenic factors should be dependent on the length of time plants have acted upon their environment. This effect can be demonstrated both during short time periods $(<10 \mathrm{yr}$ ), as shown here, and for much longer time periods (cf. Den Hartog 1971). In addition, the importance of plant-mediated changes in habitat conditions should be greater within larger seagrass patches. Thus, the importance of autogenic effects on plant development increases with increasing patch size and age.

In summary, our results demonstrate the importance of autogenic factors for seagrass recovery by providing evidence of the importance of seagrass recruitment and mortality for patch development, and by providing evidence suggesting an intrinsic, probably density-dependent, upper limit to seagrass development. These patterns, more difficult to demonstrate in already established seagrass meadows, stress the need to quantify seagrass effects on habitat conditions to correct the present imbalance of our knowledge of seagrass growth control, largely derived from the study of environmental influences on seagrass growth.

Acknowledgements. This work was supported by a research grant of the CSIC to C.M.D., and by a SNF grant to K.S.J. We thank $J$. Romero and $M$. Perez for advice; $B$. Vidondo, $S$ Agusti, T Jespersen, T Sand-Jespersen, J. Duarte, and G. Duarte for field and laboratory assistance; S. Williams and an anonymous reviewer for helpful comments, and J. Borum for helpful comments and supplies

\section{LITERATURE CITED}

Caye, G. Meinesz, A. (1985). Observations on the vegetative development, flowering and seeding of cymodocea nod osa (Ucria) Ascherson on the Mediterranean coasts of France. Aquat. Bot. 22: 277-289

Cleveland, W S. (1979). Robust locally weighted regression and smoothing scatterplots. J. Am. Stat. Assoc. 74: 829-836

Den Hartog, C. (1971). The dynamic aspect in the ecology of sea-grass communities. Thalassia Jugoslavica 7 - 101-112

Duarte, C. M. (1989). Temporal biomass variability and production/biomass relationships of seagrass communities. Mar Ecol. Prog. Ser 51:269-276

Duarte, C. M. (1990). The ecological implications of submerged macrophyte growth-form. Aquat. Bot. (in press)

Duarte, C. M., Kalff, J. (1987). Weight-density relationshıps in submerged macrophytes. The importance of light and plant geometry. Oecologia (Berl.) 72: 612-617

Duarte, C. M., Sand-Jensen, K. (1990). Seagrass colonization patch formation and patch growth in Cymodocea nodosa. Mar. Ecol. Prog. Ser 65: 193-200

Fonseca, M. S., Fisher, J. J., Zieman, J. C., Thayer, G. W 
(1982). Influence of the seagrass, Zostera marina L., on current flow. Estuar coast. Shelf Sci. 15: 351-364

Fonseca, M. S., Zieman, J, C., Thayer, G. W., Fisher, J. S. (1983). The role of current velocity in structuring seagrass (Zostera marina L.) meadows. Estuar. coast. Shelf Sci. 17: $367-380$

Ovington, J. D. (1953). A study of invasion by Holcus mollis L. J. Ecol. 41: 35-52

Orth, R. J. (1977). The importance of sediment stability in seagrass communities. In Coull, B. C. (ed.) Ecology of marine benthos. Univ. South Carolina Press, Columbia. p. $281-300$

Perez, M. (1989). Fanerogamas marinas en sistemas estuaricos: produccion, factores limitantes y algunos aspectos del ciclo de nutrientes. Ph.D. thesis, Universidad de Barcelona, Barcelona

Short, F. T. (1980). A simulation model of the seagrass production system. In: Phillips, R. C., McRoy, C. P., (eds.) Handbook of seagrass biology: an ecosystem perspective. Garland, New York, p. 277-295

Stevenson, J. C. (1988). Comparative ecology of submerged

This article was presented by Dr G.W. Thayer, Beaufort, N. Carolina, USA grass beds in freshwater, estuarine, and marine environments. Limnol. Oceanogr 33: 867-893

Thayer, G. W., Kenworthy, W. J., Fonseca, M. S. (1984). The ecology of eelgrass meadows of the Atlantic coast: a community profile. U.S. Fish Wildl. Serv. FWS/OBS-84/02: $1-147$

Tomlinson, P. B. (1974). Vegetative morphology and meristem dependence - the foundation of productivity in seagrasses. Aquaculture 4: 107-130

Wetzel, R. L., Neckles, H. (1986). A model of Zostera marina L. photosynthesis and growth: simulated effects of selected physical-chemical variables and biological interactions. Aquat. Bot. 26: 307-323

Zieman, J. C., Jr. (1972). Origin of circular beds of Thalassia (Spermatophyta: Hydrocharitaceae) in South Biscaine Bay, Florida, and their relationship to mangrove hammocks. Bull. mar. Sci. 22: 559-574

Zimmermann, R. C., Smith, R. D., Alberte, R. S. (1987). Is growth of eelgrass nitrogen limited? A numerical simulation of the effects of light and nitrogen on growth dynamics of Zostera marina. Mar Ecol. Prog. Ser 41: 167-176.

Manuscript first received: January 30, 1990

Revised version accepted: June 29, 1990 